Article

\title{
Strength, Jumping and Change of Direction Speed Asymmetries in Soccer, Basketball and Tennis Players
}

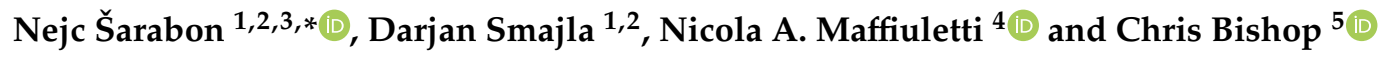 \\ 1 Faculty of Health Sciences, University of Primorska, 6310 Izola, Slovenia; darjan.smajla@fvz.upr.si \\ 2 S2P, Science to Practice, Ltd., Laboratory for Motor Control and Motor Behaviour, 1000 Ljubljana, Slovenia \\ 3 InnoRenew CoE, Livade 6, 6310 Izola, Slovenia \\ 4 Human Performance Lab, Schulthess Clinic, 8008 Zurich, Switzerland; nicola.maffiuletti@kws.ch \\ 5 London Sport Institute, Middlesex University, Greenlands Lane, Allianz Park, London NW4 4BT, UK; \\ c.bishop@mdx.ac.uk \\ * Correspondence: nejc.sarabon@fvz.upr.si; Tel.: +386-(0)40-429-505
}

Received: 23 September 2020; Accepted: 10 October 2020; Published: 12 October 2020

check for updates

\begin{abstract}
Despite growing research in the field of inter-limb asymmetries (ILAs), little is known about the variation of ILAs in different populations of athletes. The purpose of this study was to compare ILAs among young basketball, soccer and tennis players. ILAs were assessed in three different types of tests (strength, jumping and change of direction (CoD) speed), each including different tasks: (1) bilateral and unilateral counter movement jump, (2) isometric strength of knee extensors (KE) and knee flexors (KF), and (3) $90^{\circ}$ and $180^{\circ} \mathrm{CoD}$. Generally, the absolute metrics showed strong reliability and revealed significant differences $(p<0.05)$ among the three groups in KE maximal torque, KE and KF rate of force development and in both CoD tests. For jumping ILAs, power and force impulse metrics exhibited significant between-limb differences between groups, compared to jump height. For strength and CoD speed ILAs, only KF maximal torque and $180^{\circ} \mathrm{CoD}$ exhibited significant differences between groups. Greater KF strength ILAs in soccer players and counter-movement jump ILAs in tennis players are most probably the result of sport-specific movement patterns and training routines. Sport practitioners should be aware of the differences in ILAs among sports and address training programs accordingly.
\end{abstract}

Keywords: bilateral asymmetry; strength; power; agility; speed

\section{Introduction}

Inter-limb asymmetry (ILA), which refers to the difference in performance or function of one limb relative to the other [1], has been a popular topic in recent years. Numerous methods of assessment have been used to quantify ILA, ranging from the back squat [2] and isokinetic dynamometry [3] for strength, bilateral and unilateral countermovement $\left(\mathrm{CMJ}_{\mathrm{BL}}\right.$ and $\left.\mathrm{CMJ}_{\mathrm{UL}}\right)$ and drop jumps [4-7] for jumping, and the " 505 " test [8] for change of direction (CoD) speed. These methods have been a common choice for assessing ILA in athlete populations, owing to the importance of strength [9], power [10] and $\mathrm{CoD}$ speed [11] performance in sport.

There is an abundance of literature highlighting the variable and task-specific nature of ILA $[7,12-14]$. Thus, the selection of multiple tests seems advisable when quantifying ILA to provide a meaningful picture of any existing differences. For example, during back squat, greater ILAs in vertical ground reaction force were seen in the subjects who started the lift with uneven weight distribution (4.4-4.9\%), compared to those who had symmetrical weight distribution (2.1-2.5\%) [2]. Similar values were noted for peak force $(2.8 \%)$ during a unilateral isometric mid-thigh pull task in collegiate athletes [5]. However, impulse at epochs of 200 and 300 milliseconds from contraction onset 
showed much greater ILAs (6.0-7.2\%) [13]. Jumping and CoD speed tasks have also shown varying levels of ILA [14]. For example, Lockie et al. (2014) reported ILA scores of 10.4, 5.1 and 3.3\% for the $\mathrm{CMJ}_{\mathrm{UL}}$, lateral and broad jump, respectively, which confirm the variability between unilateral jump tasks often reported in previous studies $[5,12,13,15]$. For $\mathrm{CoD}$ speed, it has been suggested that total time may not be overly sensitive at detecting existing ILAs $[8,13,16]$, with mean values $>3 \%$ rarely being reported. Thus, given the inherent differences in ILA values which may arise from different tests, it is advised that a battery of tests is used, rather than a single test, to provide a more meaningful picture of the task-specific nature of ILA.

Despite the abundant literature pertaining to the magnitude of ILAs $[2,7,17,18]$, little is known about how ILA may vary between different populations of athletes. Comparison of ILAs between different populations of athletes can help providing guidelines for optimized training programmes, as specific movement patterns and training regimes in each sport may lead to different ILAs. Moreover, analysing ILAs with various tests on large samples of athletes can potentially reveal the most sensitive tests for ILA detection. Bishop et al. [8] conducted an inter-sport comparison of professional soccer and cricket athletes, measuring jump ILAs with $\mathrm{CMJ}_{\mathrm{UL}}$ and drop jump. No significant differences in ILA were evident between sports for the $\mathrm{CMJ}_{\mathrm{UL}}$. However, cricket athletes showed significantly greater ILAs in jump height (11.5 vs. 6.5\%) and reactive strength (10.4 vs. $5.9 \%)$ for the drop jump. Dos Santos et al. [19] compared ILAs for total time and CoD deficit metrics (from the "505" test) between basketball, soccer, and cricket athletes. Total time exhibited ILAs of 3.3-4.8\% across sports. In contrast, $\mathrm{CoD}$ deficit showed ILAs of $18.5-28.4 \%$ across sports. Collectively, these data indicate that jump height, reactive strength (unilateral drop jump) and CoD deficit (" 505 " test) may be useful metrics for detecting meaningful differences in ILAs between sports. However, further comparisons between sports are warranted.

All the aforementioned studies used healthy populations with relatively small sample sizes (less than 50 participants, with the exception of Dos'Santos et al. [19] who evaluated 115 participants of both sexes from four different sports). Evaluating larger groups of athletes may provide a more meaningful picture of both the magnitude and direction of ILAs for sport-related comparisons. Strength, power and speed are important abilities for soccer [20], basketball [21] and tennis players [22]. Therefore, the aim of the present study was to compare different ILAs among a large sample of young basketball, soccer and tennis players, specifically considering three different types of tests (jumping, strength and $\mathrm{CoD}$ speed), each including different tasks: (a) $\mathrm{CMJ}_{\mathrm{BL}}$ and $\mathrm{CMJ}_{\mathrm{UL}}$ (b) isometric strength of knee extensors (KE) and knee flexors (KF), and (c) $90^{\circ}$ and $180^{\circ} \mathrm{CoD}$. The study idea was built around two practical questions: (1) which test and outcome measure has the best sensitivity to detect ILAs? (2) Are there sport-specific ILAs in young soccer, tennis, and basketball players that need special attention?

\section{Materials and Methods}

\subsection{Subjects}

A total of 268 young healthy male athletes from basketball $(\mathrm{n}=101,16.8 \pm 1.2$ years, $188.7 \pm 8.5 \mathrm{~cm}$, $80.0 \pm 12.6 \mathrm{~kg}$, BMI: $22.4 \pm 2.6$, training years: $6.6 \pm 2.5$, left preferred: 83 , right preferred: 18$)$, soccer $(\mathrm{n}=113,16.7 \pm 1.2$ years, $180.1 \pm 6.8 \mathrm{~cm}, 70.3 \pm 8.7 \mathrm{~kg}$, BMI: $21.6 \pm 2.1$, training years: $9.2 \pm 2.4$, left preferred: 80, right preferred: 33$)$ and tennis $(\mathrm{n}=54,16.2 \pm 2.8$ years, $177.1 \pm 8.1 \mathrm{~cm}, 66.2 \pm 10.9 \mathrm{~kg}$, BMI: $21.0 \pm 2.4$, training years: $9.1 \pm 3.5$, left preferred: 39 , right preferred: 15 ) were included in the study. Leg side preference was determined with the question: "Which leg do you use for take-off during unilateral jumping movements?" The main exclusion criteria were lower limb injuries in the past 6 months, any neurological disorders, low back pain or recent general illness. Subjects and their parents/guardians (in case subjects were under the age of 18) were informed about the testing procedures and provided written informed consent prior to commencing the study. Subjects were asked to refrain from intense physical activities at least $48 \mathrm{~h}$ prior to testing. The experiment was 
approved by Slovenian Medical Ethics Committee (approval no. 0120-99/2018/5) and was conducted according to the Declaration of Helsinki.

\subsection{Study Design}

A cross sectional study was conducted to compare ILAs between evaluated sports. Absolute and relative within-session reliability (using the three trials per condition) of the absolute outcome measures was evaluated for each sport group. A between-groups repeated-measures research design was used to compare the absolute differences and ILAs between sport groups. Subjects were asked to attend a single test session that lasted approximately $1 \mathrm{~h}$. They first completed a 20-min warm up (10 min of light running, 5 min of dynamic stretches of ankle extensors, knee flexors, knee extensors and hip flexors and 5 min of activation exercises such as maximal squat jumps, counter movement jumps and jump push-ups). They were then asked to perform jumping, strength and CoD speed tests in a random order: $\mathrm{CMJ}_{\mathrm{BL}}$ and $\mathrm{CMJ} \mathrm{JL}_{\mathrm{U}}$ for jumping, $\mathrm{KE}$ and $\mathrm{KF}$ for strength and $90^{\circ}$ and $180^{\circ}$ turns for CoD. Task execution was randomly presented in each test (preferred vs. non-preferred leg). At the end of the warm-up, subjects underwent 3 familiarization trials of CMJ and CoD tasks that were performed progressively at 50,75 , and $90 \%$ of maximal effort (based on their subjective feeling). The familiarization trials were performed to offer the athlete the possibility to realize a medium, high-intensity and a quasi-maximal intensity trial before measurements. For the KE and KF strength tasks, the familiarization protocol was performed directly on the dynamometer before the main testing trials.

\subsection{Testing Procedures}

\subsubsection{Strength}

For the strength tests, subjects were seated in an isometric knee dynamometer (S2P, Science to Practice Ltd., Ljubljana, Slovenia) equipped with two force transducers (1-Z6FC3/200 kg, Hottinger-Baldwin Messtechnik GmbH, Darmstadt, Germany), one per side. The knee angle was set to $60^{\circ}$ of flexion and hips were flexed at $90^{\circ}$. The mechanical axis of the dynamometer was aligned with the subject's knee axis of rotation utilizing the medial femoral epicondyle as a reference. The distal shin pad of the dynamometer lever arm was attached with a strap 3-5 $\mathrm{cm}$ proximal to the medial malleolus. Subjects were held into the testing position by a tight belt across the pelvis, and additional belts just above the knee. They were asked to hold the hand grips along the seat, whose position was individually adjusted [23]. Before the test trials, subjects completed a specific warm-up/familiarization protocol consisting of 3 submaximal trials (for each condition) at 50,75 and 90\% of their estimated maximal torque $\left(\mathrm{T}_{\max }\right)$. They then performed 3 maximal voluntary contractions (MVC) per task (KE and KF) and side (preferred and non-preferred) in a random order (12 MVCs in total). They were carefully instructed to push/pull against the shin pad as fast and hard as possible for $\sim 3 \mathrm{~s}$ and to passively rest for $60 \mathrm{~s}$ between each contraction. Loud verbal encouragement and real-time visual feedback of the force-time curve were consistently provided. The signals from the force transducers were sampled at $1000 \mathrm{~Hz}$ (ARS Software, S2P, Science to Practice Ltd., Ljubljana, Slovenia) and low-pass filtered with a Butterworth filter $(20 \mathrm{~Hz}$ cut-off frequency, 2nd order). For each MVC, a 1-s time interval around $\mathrm{T}_{\max }$ was automatically selected by the software and the average torque during this interval was recorded $\left(T_{\max }\right)$. Peak rate of torque development (RTD) was also quantified as the highest positive value from the first derivative of the torque signal (i.e., the greatest slope of the torque-time curve). Trials were disregarded if baseline torque changed by more than $2.5 \mathrm{Nm}$ in the $200 \mathrm{~ms}$ prior to the MVC and if the maximal torque plateau was not sustained for at least $1.5 \mathrm{~s}$.

\subsubsection{Bilateral and Unilateral Countermovement Jump}

The jumping tests were performed on a bilateral force plate (Kistler, model 9260AA6, Winterthur, Switzerland). Before the test trials, subjects completed 3 warm-up/familiarization trials (for each 
condition) at $80 \%$ of their estimated maximal effort. Then, they performed 3 maximal $\mathrm{CMJ}_{\mathrm{BL}}$ followed by $3 \mathrm{CMJ}_{\mathrm{UL}}$ with the preferred and non-preferred leg in a random order ( $9 \mathrm{CMJs}$ in total). They were carefully instructed to jump as high as possible and to passively rest for $30 \mathrm{~s}$ between each jump. Loud verbal encouragement was consistently provided to ensure maximum effort. If the jump test instructions were not respected (quiet standing period for 1-2 $\mathrm{s}$ before the start, hands on hips all time, take-off leg(s) fully extended during flight phase, no swing of the contralateral leg in $\mathrm{CMJ}_{\mathrm{UL}}$ ), the subject was asked to repeat the jump [6]. Data from the force plates were sampled at $1000 \mathrm{~Hz}$ and low pass filtered with a Butterworth filter ( $10 \mathrm{~Hz}$ cut-off frequency, 2nd order). The following outcome measures were automatically calculated from the force-time data in the acquisition software (MARS, Kistler, Winterthur, Switzerland): jump height $(\mathrm{H})$ from flight time $\left(\mathrm{CMJ}_{\mathrm{UL}}\right.$ only), mean power $(\mathrm{P})$ normalized to body weight (CMJ $\mathrm{UL}_{\mathrm{UL}}$ only) and force impulse (FI) normalized to body weight $\left(\mathrm{CMJ} \mathrm{JL}_{\mathrm{UL}}\right.$ and $\mathrm{CMJ}_{\mathrm{BL}}$ ).

\subsubsection{0 and $180^{\circ}$ Change of Direction Speed}

CoD tests were performed in a gym (tartan floor) and were timed using photocell timing gates (Brower Timing Systems, Draper, UT, USA). Gates were placed at about hip height and the starting line was $0.5 \mathrm{~m}$ behind the first timing gate to prevent early triggering. Before the test trials, subjects completed two warm-up/familiarization trials (for each condition) at 50 and $75 \%$ of their maximal speed. They then performed 3 maximal CoD trials per side turn (preferred and non-preferred, executed in alternate order) and tasks ( 90 and $180^{\circ}$ turn, randomly presented), with rest periods of 1 and 3 min between consecutive trials and tasks, respectively (12 trials in total). For the CoD $90^{\circ}$, subjects were instructed to place either the preferred or non-preferred foot on the middle of the starting line, sprint around the cone, make a $90^{\circ}$ turn on one of the two sides and sprint through the finish line. The distance from the first timing gate to the cone (point of $\mathrm{CoD}$ ), and from the cone to the second timing gate was $5 \mathrm{~m}$, for a total distance of $10 \mathrm{~m}$. For the CoD $180^{\circ}$, subjects sprinted around the cone and back to the first timing gate (10 $\mathrm{m}$ in total). Loud verbal encouragement was consistently provided to ensure maximum effort. For each task ( 90 and $180^{\circ}$ turn) and side (preferred, non-preferred), the main outcome measure was the total time (s) [8].

\subsection{Statistical Analyses}

For all the outcome measures (CMJ H, CMJ P, CMJ FI, T $\max$, RTD, CoD time), the average value of the three trials for each task and side was considered for calculating ILA, according to this equation [12]:

$$
\operatorname{ILA}(\%)=\left(\frac{\max (\text { preferred or non }- \text { preferred })-\min (\text { preferred or non }- \text { preferred })}{\max (\text { preferred or non-preferred })}\right) \times 100
$$

Statistical analyses were performed in SPSS (Version 20, IBM, Armonk, NY, USA) and MatLab (Version 2018a, Mathworks, Natick, MA, USA). The minimal total sample size for comparison of three independent groups was calculated to be 128 , based on the small to moderate effect size (0.25), alpha error of 0.05 and desired statistical power at 0.8 . Absolute and relative within-session reliability (using the three trials per condition) of the absolute outcome measures was evaluated using coefficients of variation (CV) with $95 \%$ confidence intervals and two-way random intraclass correlation coefficients (ICC) with $95 \%$ confidence intervals (CI), respectively. CV values $<10 \%$ were deemed acceptable [24]. ICCs were arbitrarily interpreted according to Koo and Li (2015) [25], where ICC $>0.90=$ excellent, $0.75-0.90=$ good, $0.50-0.74=$ moderate and $<0.50=$ poor. Taking into account the non-normal distribution of ILA data, differences between sport disciplines were assessed with $\chi^{2}$ tests and post-hoc pairwise comparisons with Bonferroni correction. Differences in absolute data were analyzed with repeated measures ANOVA followed by Bonferroni post-hoc comparisons. For each outcome measure-including ILA—we calculated Hedges $g$ with $95 \%$ CI to evaluate the magnitude of difference between groups. For all analyses, the level of significance was set at $p<0.05$. 


\section{Results}

\subsection{Reliability}

The reliability results for the main outcome measures are presented in Table 1 by sport discipline. In general, absolute reliability showed acceptable CV values $(<10 \%)$ for most outcome measures. However, RTD showed CVs $>10 \%$ in some instances (KE RTD of preferred leg in tennis players, KE RTD and KF RTD of preferred leg and KF RTD of non-preferred leg in basketball players). For relative reliability, a similar trend was observed with good to excellent ICCs for most of the outcome measures, apart from some RTD metrics, which showed moderate reliability.

\subsection{Comparison of Absolute Outcome Measures between Sport Disciplines}

The main results for each sport discipline and between sport differences with effects sizes are presented in Table 2. There were no consistent significant differences between groups for jumping performance. Tennis players showed greater strength for KE, but not for KF, compared to basketball and soccer players. Moreover, soccer players showed greater strength for all the outcome measures except KF $\mathrm{T}_{\text {max }}$ of the non-preferred leg. For CoD speed, tennis players were slower for all the outcomes except $90^{\circ} \mathrm{CoD}$ in direction of push off with preferred leg. Basketball players were faster compared to soccer players in $90^{\circ} \mathrm{CoD}$ but not in $180^{\circ} \mathrm{CoD}$.

\subsection{Comparison of ILA between Sport Disciplines}

Mean ILA by sport discipline and effect sizes for differences between groups are presented in Table 3, while individual data are presented in Figure 1. Our results revealed greater jumping ILAs for $\mathrm{CMJ}_{\mathrm{UL}} \mathrm{FI}$ and $\mathrm{P}$ in tennis players compared to basketball and soccer players, contrary to $\mathrm{CMJ}_{\mathrm{BL}} \mathrm{H}$ and $\mathrm{CMJ}_{\mathrm{UL}} \mathrm{H}$ for which no significant difference was observed. Analysis of strength ILAs showed that KE outcome measures were not sensitive enough to detect between group differences. Conversely, soccer players had greater ILA for KF (both $\mathrm{T}_{\max }$ and RTD) compared to basketball players. Moreover, $180^{\circ} \mathrm{CoD}$ ILAs were greater in basketball players compared to soccer and tennis players, while no difference was observed for $90^{\circ} \mathrm{CoD}$. 
Table 1. Reliability results by sport discipline.

\begin{tabular}{|c|c|c|c|c|c|c|c|}
\hline & \multirow{2}{*}{ Test } & \multicolumn{2}{|c|}{ Basketball } & \multicolumn{2}{|c|}{ Soccer } & \multicolumn{2}{|c|}{ Tennis } \\
\hline & & CV (\%) & ICC (95\% CI) & CV (\%) & ICC $(95 \%$ CI $)$ & CV (\%) & ICC $(95 \%$ CI $)$ \\
\hline \multirow{3}{*}{$\mathrm{CMJ}_{\mathrm{BL}}$} & Jumping: & & & & & & \\
\hline & $\mathrm{FI}_{\mathrm{P}}$ & 1.13 & $0.94(0.83,0.96)$ & 1.66 & $0.91(0.86,0.93)$ & 1.57 & $0.94(0.90,0.97)$ \\
\hline & $\mathrm{FI}_{\mathrm{NP}}$ & 1.53 & $0.93(0.88,0.95)$ & 1.5 & $0.92(0.89,0.95)$ & 1.28 & $0.95(0.90,0.97)$ \\
\hline \multirow{6}{*}{$\mathrm{CMJ}_{\mathrm{UL}}$} & $\mathrm{H}_{\mathrm{P}}$ & 1.99 & $0.96(0.92,0.98)$ & 0.6 & $0.93(0.89,0.96)$ & 0.7 & $0.97(0.93,0.99)$ \\
\hline & $\mathrm{H}_{\mathrm{NP}}$ & 2.92 & $0.88(0.75,0.95)$ & 2.45 & $0.95(0.91,0.97)$ & 1.93 & $0.96(0.90,0.99)$ \\
\hline & $P_{P}$ & 1.3 & $0.96(0.93,0.97)$ & 1.84 & $0.92(0.88,0.95)$ & 0.95 & $0.98(0.94,0.99)$ \\
\hline & $\mathrm{P}_{\mathrm{NP}}$ & 0.89 & $0.97(0.95,0.98)$ & 2 & $0.92(0.88,0.95)$ & 2 & $0.93(0.82,0.98)$ \\
\hline & $\mathrm{FI}_{\mathrm{P}}$ & 1.22 & $0.94(0.91,0.96)$ & 1.38 & $0.93(0.90,0.95)$ & 1.07 & $0.96(0.93,0.98)$ \\
\hline & $\mathrm{FI}_{\mathrm{NP}}$ & 1.01 & $0.95(0.92,0.96)$ & 1.29 & $0.93(0.89,0.95)$ & 1.3 & $0.97(0.95,0.98)$ \\
\hline \multirow{5}{*}{ KE } & Strength: & & & & & & \\
\hline & $\mathrm{T}_{\operatorname{maxP}}$ & 2.53 & $0.92(0.87,0.95)$ & 3.75 & $0.83(0.75,0.89)$ & 1.47 & $0.95(0.92,0.97)$ \\
\hline & $\mathrm{T}_{\operatorname{maxNP}}$ & 2.02 & $0.94(0.89,0.96)$ & 2.01 & $0.94(0.91,0.96)$ & 1.83 & $0.96(0.93,0.98)$ \\
\hline & RTD $_{\mathrm{P}}$ & 12.45 & $0.66(0.50,0.77)$ & 9.89 & $0.80(0.71,0.86)$ & 15.77 & $0.65(0.40,0.82)$ \\
\hline & $\mathrm{RTD}_{\mathrm{NP}}$ & 9.66 & $0.77(0.66,0.85)$ & 7.24 & $0.87(0.81,0.91)$ & 8.6 & $0.64(0.22,0.82)$ \\
\hline \multirow{4}{*}{ KF } & $\mathrm{T}_{\operatorname{maxP}}$ & 1.29 & $0.96(0.93,0.97)$ & 1.5 & $0.96(0.94,0.98)$ & 1.98 & $0.95(0.90,0.97)$ \\
\hline & $\mathrm{T}_{\operatorname{maxNP}}$ & 1.33 & $0.96(0.94,0.97)$ & 0.98 & $0.98(0.97,0.99)$ & 1.43 & $0.96(0.93,0.98)$ \\
\hline & RTD $_{\mathrm{P}}$ & 17.97 & $0.66(0.49,0.77)$ & 9.71 & $0.79(0.70,0.86)$ & 8.86 & $0.86(0.66,0.89)$ \\
\hline & $\mathrm{RTD}_{\mathrm{NP}}$ & 12.67 & $0.77(0.65,0.84)$ & 8.51 & $0.79(0.70,0.86)$ & 4.12 & $0.80(0.66,0.89)$ \\
\hline \multirow{5}{*}{ CoD } & Speed: & & & & & & \\
\hline & $90_{\mathrm{P}}$ & 1.23 & $0.93(0.89,0.95)$ & 1.87 & $0.85(0.79,0.89)$ & 0.91 & $0.95(0.92,0.97)$ \\
\hline & $90_{\mathrm{NP}}$ & 1.94 & $0.84(0.77,0.89)$ & 1.85 & $0.86(0.79,0.91)$ & 0.78 & $0.96(0.94,0.98)$ \\
\hline & $180_{\mathrm{P}}$ & 1.38 & $0.90(0.86,0.93)$ & 1.5 & $0.85(0.80,0.89)$ & 1.04 & $0.93(0.88,0.95)$ \\
\hline & $180_{\mathrm{NP}}$ & 1.61 & $0.86(0.80,0.90)$ & 1.23 & $0.88(0.84,0.92)$ & 1.04 & $0.93(0.89,0.96)$ \\
\hline
\end{tabular}

Note: $\mathrm{CMJ}_{\mathrm{BL}}$-bilateral counter movement jump, $\mathrm{CMJ}$ UL —unilateral counter movement jump, KE—knee extensors, KF-knee flexors, H—jump height, P—average power, FI—force impulse, Tmax - maximal torque, RTD—rate of torque development, CoD—change of direction, 90 —change of direction at $90^{\circ}, 180$ —change of direction at $180^{\circ}$, $\mathrm{p}$ - performance with preferred leg/in preferred direction, NP - performance with non-preferred leg/in not-preferred direction, CV (\%)—coefficient of variability, ICC-interclass correlation coefficient, $95 \%$ CI-95\% confidence interval. 
Table 2. Outcome measures by sport discipline and effect sizes for differences between sports.

\begin{tabular}{|c|c|c|c|c|c|c|c|}
\hline & \multirow[b]{2}{*}{ Test } & \multicolumn{3}{|c|}{ Mean \pm SD } & \multicolumn{3}{|c|}{ Hedges g $(95 \% \mathrm{CI})$} \\
\hline & & Basketball (B) & Soccer (S) & Tennis (T) & B vs. S & B vs. T & S vs. T \\
\hline \multirow[b]{2}{*}{$\mathrm{CMJ}_{\mathrm{BL}}$} & Jumping: & & & & & & \\
\hline & $\mathrm{FI}_{\mathrm{P}}(\mathrm{Ns} / \mathrm{kg})$ & $1.21 \pm 0.11$ & $1.24 \pm 0.11$ & $1.20 \pm 0.13$ & $-0.28(-0.50,-0.05)$ & $0.07(-0.16,0.29)$ & $0.33(0.10,0.55)$ * \\
\hline \multirow{5}{*}{$\mathrm{CMJ}_{\mathrm{UL}}$} & $\mathrm{H}_{\mathrm{P}}(\mathrm{cm})$ & $16.08 \pm 3.31$ & $16.77 \pm 3.38$ & $15.90 \pm 3.91$ & $-0.21(-0.43,0.0)$ & $0.05(-0.23,0.33)$ & $0.24(-0.03,0.57)$ \\
\hline & $\mathrm{H}_{\mathrm{NP}}(\mathrm{cm})$ & $15.61 \pm 2.84$ & $16.74 \pm 3.65$ & $15.51 \pm 3.71$ & $-0.34(-0.57,-0.12) *$ & $0.03(-0.25,0.31)$ & $0.33(0.06,0.61)$ * \\
\hline & $\mathrm{P}_{\mathrm{P}}(\mathrm{W} / \mathrm{kg})$ & $16.12 \pm 2.43$ & $16.60 \pm 2.21$ & $16.02 \pm 2.81$ & $-0.21(-0.43,0.02)$ & $0.04(-0.24,0.32)$ & $0.24(-0.03,0.51)$ \\
\hline & $\mathrm{P}_{\mathrm{NP}}(\mathrm{W} / \mathrm{kg})$ & $16.02 \pm 2.37$ & $16.47 \pm 2.42$ & $16.19 \pm 2.84$ & $-0.19(-0.41,0.04)$ & $-0.06(-0.34,0.21)$ & $0.11(-0.16,0.38)$ \\
\hline & $\mathrm{FI}_{\mathrm{NP}}(\mathrm{Ns} / \mathrm{kg})$ & $1.69 \pm 0.18$ & $1.71 \pm 0.20$ & $1.71 \pm 0.27$ & $-0.09(-0.32,0.13)$ & $-0.06(-0.29,0.16)$ & $0.01(-0.21,0.23)$ \\
\hline \multirow{5}{*}{$\mathrm{KE}$} & Strength: & & & & & & \\
\hline & $\mathrm{T}_{\operatorname{maxP}}(\mathrm{Nm} / \mathrm{kg})$ & $2.51 \pm 0.53$ & $2.72 \pm 0.61$ & $3.50 \pm 0.79$ & $-0.35(-0.58,-0.13)$ * & $-1.56(-1.87,-1.24)$ * & $-1.16(-1.46,-0.87) *$ \\
\hline & $\mathrm{T}_{\operatorname{maxNP}}(\mathrm{Nm} / \mathrm{kg})$ & $2.41 \pm 0.53$ & $2.78 \pm 0.66$ & $3.45 \pm 0.79$ & $-0.61(-0.84,-0.38) *$ & $-1.64(-1.95,-1.32) *$ & $-0.94(-1.22,-0.65)$ * \\
\hline & $\operatorname{RTD}_{\mathrm{P}}(\mathrm{Nm} / \mathrm{kg} \mathrm{s})$ & $11.88 \pm 4.21$ & $15.34 \pm 4.56$ & $17.60 \pm 5.20$ & $-0.78(-1.02,-0.55) *$ & $-1.24(-1.54,-0.94) *$ & $-0.47(-0.75,-0.20) *$ \\
\hline & $\operatorname{RTD}_{\mathrm{NP}}(\mathrm{Nm} / \mathrm{kg} \mathrm{s})$ & $11.48 \pm 4.10$ & $15.57 \pm 5.30$ & $17.71 \pm 5.53$ & $-0.85(-1.09,-0.62) *$ & $-1.34(-1.64,-1.03)$ * & $-0.40(-0.67,-0.12) *$ \\
\hline \multirow{3}{*}{ KF } & $\mathrm{T}_{\operatorname{maxP}}(\mathrm{Nm} / \mathrm{kg})$ & $1.59 \pm 0.30$ & $1.68 \pm 0.31$ & $1.74 \pm 0.37$ & $-0.31(-0.53,-0.08) *$ & $-0.49(-0.77,-0.21) *$ & $-0.20(-0.47,007)$ \\
\hline & $\mathrm{T}_{\operatorname{maxNP}}(\mathrm{Nm} / \mathrm{kg})$ & $1.58 \pm 0.33$ & $1.62 \pm 0.35$ & $1.72 \pm 0.47$ & $-0.14(-0.36,0.09)$ & $-0.38(-0.66,-0.11)$ * & $-0.25(-0.53,0.02)$ \\
\hline & $\operatorname{RTD}_{\mathrm{P}}(\mathrm{Nm} / \mathrm{kg} \mathrm{s})$ & $14.37 \pm 3.52$ & $18.63 \pm 5.91$ & $15.35 \pm 6.50$ & $-0.86(-1.10,-0.63)$ * & $-0.21(-0.48,0.07)$ & $0.53(0.26,0.81) *$ \\
\hline \multirow{5}{*}{$\mathrm{CoD}$} & Speed: & & & & & & \\
\hline & $90_{\mathrm{P}}(\mathrm{s})$ & $2.48 \pm 0.14$ & $2.41 \pm 0.27$ & $2.52 \pm 0.16$ & $0.33(0.10,0.55)$ * & $-0.27(-0.55,0.01)$ & $-0.46(-0.74,-0.19) *$ \\
\hline & $90_{\mathrm{NP}}(\mathrm{s})$ & $2.48 \pm 0.12$ & $2.41 \pm 0.26$ & $2.54 \pm 0.17$ & $0.30(0.08,0.53)$ * & $-0.40(-0.68,-0.12)$ * & $-0.51(-0.78,-0.23)$ * \\
\hline & $180_{\mathrm{P}}(\mathrm{s})$ & $2.96 \pm 0.15$ & $2.91 \pm 0.30$ & $3.05 \pm 0.17$ & $0.21(-0.02,0.43)$ & $-0.55(-0.83,-0.26)$ * & $-0.51(-0.79,-0.24) *$ \\
\hline & $180_{\mathrm{NP}}(\mathrm{s})$ & $2.96 \pm 0.15$ & $2.91 \pm 0.29$ & $3.03 \pm 0.17$ & $0.20(-0.02,0.43)$ & $-0.43(-0.71,-0.15)$ * & $-0.45(-0.72,-0.17) *$ \\
\hline
\end{tabular}

Note: $\mathrm{CMJ}_{\mathrm{BL}}$-bilateral counter movement jump, $\mathrm{CMJ} \mathrm{UL}_{\mathrm{L}}$ - unilateral counter movement jump, KE—knee extensors, KF-knee flexors, $\mathrm{H}-$ jump height, $\mathrm{P} —$ average power, FI—force impulse, $\mathrm{T}_{\max }$ - maximal torque, RTD—rate of torque development, CoD—change of direction, 90 —change of direction at $90^{\circ}, 180$ - change of direction at $180^{\circ}$, $\mathrm{P}$ - performance with preferred leg/in preferred direction, NP-performance with non-preferred leg/in not-preferred direction, 95\% CI-95\% confidence interval, bold values—-significant differences based on post-hoc comparisons, * statistical significance between evaluated groups. 
Table 3. Main inter-limb asymmetry (ILA) results by sport discipline and effect sizes for differences between sports.

\begin{tabular}{|c|c|c|c|c|c|c|c|}
\hline & \multirow[b]{2}{*}{ ILA Metric } & \multicolumn{3}{|c|}{ Mean \pm SD } & \multicolumn{3}{|c|}{ Hedges g $(95 \% \mathrm{CI})$} \\
\hline & & Basketball (B) & Soccer (S) & Tennis (T) & B vs. S & B vs. $\mathrm{T}$ & S vs. $T$ \\
\hline $\mathrm{CMJ}_{\mathrm{BL}}$ & $\begin{array}{l}\text { Jumping: } \\
\text { FI (\%) }\end{array}$ & $5.4 \pm 4.2$ & $6.2 \pm 5.0$ & $6.6 \pm 5.6$ & $-0.17(-0.40,0.05)$ & $-0.26(-0.54,0.02)$ & $-0.09(-0.36,0.19)$ \\
\hline $\mathrm{CMJU}_{\mathrm{UL}}$ & $\begin{array}{l}\mathrm{H}(\%) \\
\mathrm{P}(\%) \\
\mathrm{FI}(\%)\end{array}$ & $\begin{array}{l}8.5 \pm 6.5 \\
6.2 \pm 4.8 \\
5.0 \pm 3.7\end{array}$ & $\begin{array}{l}8.6 \pm 6.9 \\
6.3 \pm 4.9 \\
5.8 \pm 4.8\end{array}$ & $\begin{array}{l}8.3 \pm 6.2 \\
8.1 \pm 7.3 \\
7.7 \pm 6.7\end{array}$ & $\begin{array}{l}-0.02(-0.24,0.21) \\
-0.02(-0.25,0.20) \\
-0.19(-0.42,0.03)\end{array}$ & $\begin{array}{c}0.03(-0.25,0.31) \\
-0.31(-0.59,-0.04) \\
-0.56(-0.84,-0.27)\end{array}$ & $\begin{array}{c}0.05(-0.23,0.32) \\
-0.30(-0.57,-0.02) * \\
-0.35(-0.63,-0.08) *\end{array}$ \\
\hline $\mathrm{KE}$ & $\begin{array}{l}\text { Strength: } \\
\mathrm{T}_{\max }(\%) \\
\operatorname{RTD}(\%)\end{array}$ & $\begin{array}{l}11.5 \pm 8.4 \\
19.5 \pm 14.4 \\
\end{array}$ & $\begin{array}{c}10.7 \pm 7.9 \\
18.0 \pm 13.4 \\
\end{array}$ & $\begin{array}{c}10.3 \pm 7.6 \\
16.2 \pm 10.4 \\
\end{array}$ & $\begin{array}{l}0.11(-0.12,0.33) \\
0.11(-0.11,0.34) \\
\end{array}$ & $\begin{array}{l}0.15(-0.13,0.43) \\
0.25(-0.03,0.53)\end{array}$ & $\begin{array}{l}0.05(-0.22,0.32) \\
0.14(-0.13,0.41)\end{array}$ \\
\hline $\mathrm{KF}$ & $\begin{array}{l}\mathrm{T}_{\max }(\%) \\
\operatorname{RTD}(\%)\end{array}$ & $\begin{array}{c}10.4 \pm 7.9 \\
15.7 \pm 10.6\end{array}$ & $\begin{array}{l}12.6 \pm 10.4 \\
18.7 \pm 14.0\end{array}$ & $\begin{array}{c}10.6 \pm 9.1 \\
17.3 \pm 15.1\end{array}$ & $\begin{array}{l}-0.24(-0.46,-0.01) \\
-0.24(-0.46,-0.01)\end{array}$ & $\begin{array}{c}0.02(-0.30,0.26) \\
-0.13(-0.41,0.15)\end{array}$ & $\begin{array}{l}0.21(-0.07,0.48) \\
0.10(-0.18,0.37)\end{array}$ \\
\hline $\mathrm{CoD}$ & $\begin{array}{l}\text { Speed: } \\
90(\%) \\
180(\%)\end{array}$ & $\begin{array}{l}2.6 \pm 2.4 \\
2.3 \pm 2.3\end{array}$ & $\begin{array}{l}2.4 \pm 2.2 \\
1.7 \pm 1.4\end{array}$ & $\begin{array}{l}2.1 \pm 1.5 \\
1.4 \pm 1.3\end{array}$ & $\begin{array}{l}0.11(-0.11,0.34) \\
0.36(0.13,0.58)\end{array}$ & $\begin{array}{l}0.25(-0.03,0.52) \\
\mathbf{0 . 4 4}(\mathbf{0 . 1 6}, \mathbf{0 . 7 2})\end{array}$ & $\begin{array}{l}0.13(-0.15,0.40) \\
0.15(-0.12,0.42)\end{array}$ \\
\hline
\end{tabular}

Note: ILA—inter-limb asymmetry, $\mathrm{CMJ}_{\mathrm{BL}}$-bilateral counter movement jump, CMJ $\mathrm{UL}_{\mathrm{L}}$-unilateral counter movement jump, KE-knee extensors, KF-knee flexors, FI—force impulse, $\mathrm{H}$-jump height, $\mathrm{P}$-average power, $\mathrm{T}_{\max }$ - maximal torque, $\mathrm{RTD}$-rate of torque development, $\mathrm{CoD}$-change of direction, 90 -change of direction at $90^{\circ}, 180$-change of direction at $180^{\circ}$,

$95 \%$ CI-95\% confidence interval ${ }^{*}$ statistical significance between evaluated groups. 


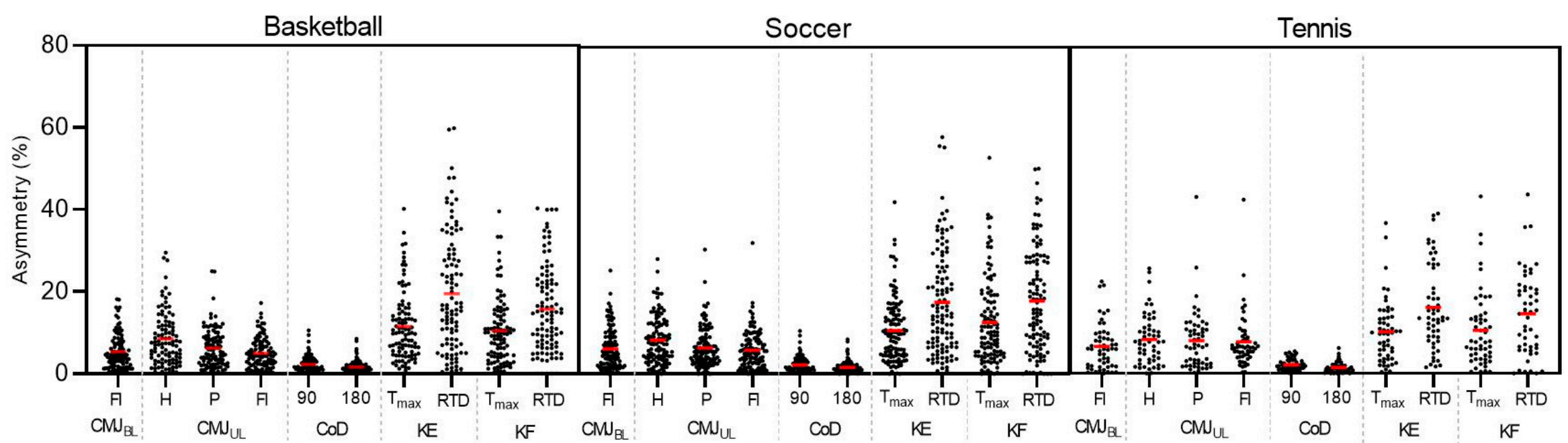

Figure 1. Jitter plots of inter-limb asymmetries for all the outcome measures. Note: $\mathrm{CMJ}_{\mathrm{BL}}$ — bilateral counter movement jump, $\mathrm{CMJ}$ UL - unilateral counter movement jump, KE—knee extensors, KF—knee flexors, H—jump height, $\mathrm{P}$-average power, FI—force impulse, $\mathrm{T}_{\text {max }}$-maximal torque, RTD—rate of torque development, CoD—change of direction, 90 - change of direction at $90^{\circ}, 180$ - change of direction at $180^{\circ}$. Red line indicates the mean value for each outcome measure. 


\section{Discussion}

The purpose of our study was to compare the magnitude of ILAs among a large sample of young basketball, soccer and tennis players, specifically considering metrics of $\mathrm{CMJ}_{\mathrm{BL}}, \mathrm{CMJ}_{\mathrm{UL}}$, isometric $\mathrm{KE}$ and $\mathrm{KF}$ strength and $\mathrm{CoD}$ speed $\left(90^{\circ}\right.$ and $\left.180^{\circ}\right)$. Significant differences among the subjects from the three different sports were seen mostly in both KE strength parameters and KF RTD, both CoD tests, while a smaller number of significant differences were seen in CMJUL for FI and $\mathrm{H}$ parameters. Differences in jumping ILA revealed that jump $\mathrm{H}$ was not sensitive enough to detect meaningful differences in asymmetries between the groups, compared to P and FI. Regarding strength-derived asymmetries, KF outcomes were sensitive enough to detect between-group differences, contrary to KE. Furthermore, ILA results in $\mathrm{CoD}$ tests revealed that $\mathrm{CoD} 180^{\circ}$ was more sensitive for detecting ILA differences between groups compared to $\mathrm{CoD} 90^{\circ}$.

The focus of our study was to provide a between-sport comparison of ILAs. Specifically, our results showed that tennis players exhibited greater P and FI ILAs in CMJUL compared to basketball and soccer players (Table 3). This difference may be a sport-specific adaptation that is more pronounced in tennis players compared to basketball or soccer. During tennis, a greater number of quick and rapid changes of direction typically occur in the lateral direction [26] compared to soccer and basketball. In addition, given that tennis players perform more actions on their forehand side [27], this imbalance in movement may be a possible reason for the elevated ILA compared to the two other sports. Jump H ILA from single-leg CMJs have already been reported in young tennis players in previous studies [16,28] (around 15\%), while slightly smaller ILAs were seen in our group of tennis players (around 8\%). However, it seems that FI and P parameters were able to detect ILA differences between sports in single CMJ performance, with lower ILAs in soccer and basketball compared to tennis. The second evident difference in ILAs between groups was observed for KF muscle strength. It is well-known that hamstring strain injury is one of the most common injuries in professional soccer players [29]. Moreover, because hamstring strength ILA (not only weakness alone) is a risk factors for hamstring injury in soccer [30], it was reasonable to expect large ILAs in soccer players. Our results show that young soccer players possess greater ILA in KF strength compared to basketball players (Table 3). As such, it is suggested that more attention should be paid to the implementation of hamstring injury prevention programs in young soccer players, with the intention of reducing existing ILA differences as a potential risk factor for injury [31]. The third notable difference between sports was seen in CoD $180^{\circ}$, with basketball players showing significantly greater ILAs compared to soccer and tennis players (Table 3). Even though it was previously shown that total time in CoD test is not particularly sensitive metric for detecting ILAs $[17,28]$ our results suggest that $\mathrm{CoD}$ at a greater angle $\left(180^{\circ}\right)$ may be more discriminative compared to $\mathrm{CoD}$ at $90^{\circ}$.

Comparison of absolute means scores (Table 2) revealed not only differences between sports, but also indicating which outcome measures of jumping, strength and $\mathrm{CoD}$ speed tests were better at detecting ILAs. Our results revealed that jump $\mathrm{H}$ and FI had better discriminant validity compared to $\mathrm{P}$, as soccer players had higher non-preferred jump $\mathrm{H}\left(\mathrm{CMJ}_{\mathrm{UL}}\right)$ compared to basketball and tennis players, as well as higher FI on preferred leg compared to tennis players $\left(\mathrm{CMJ}_{\mathrm{BL}}\right)$ and basketball players $\left(\mathrm{CMJ}_{\mathrm{UL}}\right)$. We confirmed that FI is a sensitive jump metric, as already suggested by previous research [32], and that jump $\mathrm{H}$ of unilateral tasks may better differentiate between groups.

Regarding isometric strength, systematic differences between groups were observed for all absolute KE outcome measures. Tennis players had significantly higher $\mathrm{T}_{\max }$ and RTD of both legs compared to basketball and soccer players, while soccer players were stronger than basketball players. Smaller differences between groups were seen for KF outcomes (higher $\mathrm{T}_{\max }$ of both legs in tennis compared to basketball players, higher RTD of both legs in soccer compared to basketball players) which may suggest better discriminant validity of KE outcome measures as compared to KF. KE muscle strength is an important factor for anterior cruciate ligament (ACL) injury prevention [33], while KE muscle weakness is one of the important risk factors for ACL injury [33]. The lower levels of KE strength for basketball and soccer players observed here could be associated to an increased risk for 
ACL injury, that has already been shown to be more common in these sports because of specific contact injury mechanisms [34] compared to tennis that has lower ACL injury rates [35]. On the other hand, $\mathrm{CoD} 90^{\circ}$ (soccer players were faster compared to basketball and tennis players in both directions) and $\mathrm{CoD} 180^{\circ}$ (basketball and soccer players were faster compared to tennis players in both directions) were equally effective at detecting significant differences between groups. However, the indicated pairwise differences may indicate sport-specific $\mathrm{CoD}$ requirements and long-term training adaptations. Specifically, $\mathrm{CoD} 180^{\circ}$ is not very common in tennis, while $\mathrm{CoD} 90^{\circ}$ is probably more frequent in soccer.

The advantage of our study is a very large sample size and between-sport comparison between more than 2 sports which provides good cross-sectional data. Moreover, our results enable us to determine whether different sports exhibit smaller/larger asymmetries as a consequence of their movement patterns. With multiple tests and metrics, we provided a very in-depth analysis of asymmetry, beyond merely outcome measures data.

One of the main limitations of our study is the relatively small sample size for tennis players which may have decreased the statistical power compared to the other groups. Moreover, our test battery did not contain linear speed assessment. Changing direction in $\operatorname{CoD} 90^{\circ}$ and $\operatorname{CoD} 180^{\circ}$ represents only a small time portion compared to the whole test time which is confounded by linear speed [15]. Therefore, linear speed assessment could provide useful additional information besides the CoD tests.

\section{Conclusions}

The purpose of this study was to compare ILAs among young basketball, soccer and tennis players. The results demonstrated that in the case of jumping ILAs, P and FI metrics detected significant between-limb differences between our three groups, compared to jump height. In strength and CoD ILAs, only maximal torque of $\mathrm{KF}$ and $180^{\circ} \mathrm{CoD}$ exhibited significant differences between groups. This study demonstrated important differences between testing approaches in view of their sensitivity to detect ILAs. Moreover, our results indicated that the magnitude of certain ILAs was greater in particular sport disciplines. These data may also be used as a guideline for selecting the most appropriate test procedures and outcomes for detecting ILAs. Of note, KF strength ILAs were larger in soccer players. In combination with the fact that the incidence of hamstring muscle injuries is higher in soccer than in the other sports, the results of our study reinforce the recommendations for injury prevention programs for soccer players. Large KF strength ILAs are expected in soccer; when detected on an individual level, it is worth considering including unilateral exercise programs to reduce the magnitude of ILAs. Overall, strength and conditioning coaches must be aware that specific and different ILAs may be generated in different sport disciplines which should be taken into account in training process. Moreover, due to specific adaptations in our evaluated sports, strength and conditioning coaches can select more appropriate tests and metrics for ILAs identification.

Author Contributions: Conceptualization, N.Š. and C.B.; methodology, N.Š., D.S. and N.A.M.; software, N.Š.; formal analysis, N.Š., C.B. and D.S.; investigation, D.S. and N.A.M.; resources, N.Š.; data curation, D.S.; writing-original draft preparation, N.Š. and D.S.; writing-review and editing, C.B. and N.A.M.; visualization, N.Š., C.B. and N.A.M.; supervision, N.Š.; project administration, N.Š.; funding acquisition, N.Š. All authors have read and agreed to the published version of the manuscript.

Funding: This research was funded by the Slovenian Research Agency, grant number L5-1845: Body asymmetries as a risk factor in musculoskeletal injury development: studying etiological mechanisms and designing corrective interventions for primary and tertiary preventive care and the research program found P5-0147 Kinesiology of monostructural, polystructural and conventional sports.

Conflicts of Interest: The authors declare no conflict of interest. 


\section{References}

1. Keeley, D.; Pulmmer, H.; Oliver, G. Predicting asymmetrical lower extremity strength deficits in college-aged men and women using common horizontal and vertical power field tests: A possible screening mechanis. J. Strength Cond. Res. 2011, 25, 1632-1637. [CrossRef]

2. Sato, K.; Heise, G. Influence of weight distribution asymmetry on the biomechanics of a barbell back squat. J. Strength Cond. Res. 2012, 26, 342-349. [CrossRef] [PubMed]

3. Ruas, C.V.; Minozzo, F.; Pinto, M.D.; Brown, L.E.; Pinto, R.S. Lower-extremity strength ratios of professional soccer players according to field position. Kinesiology 2015, 47, 188-192. [CrossRef] [PubMed]

4. Bell, D.R.; Sanfilippo, J.L.; Binkley, N.; Heiderscheit, B.C. Lean mass asymmetry influences force and power asymmetry during jumping in collegiate athletes. J. Strength Cond. Res. 2014, 28, 884-891. [CrossRef] [PubMed]

5. Bishop, C.; Read, P.; Chavda, S.; Jarvis, P.; Turner, A. Using Unilateral Strength, Power and Reactive Strength Tests to Detect the Magnitude and Direction of Asymmetry: A Test-Retest Design. Sports 2019, 7, 58. [CrossRef] [PubMed]

6. Bishop, C.; Read, P.; Chavda, S.; Jarvis, P.; Turner, A. Magnitude or Direction? Seasonal Variation of Interlimb Asymmetry in Elite Academy Soccer Players. J. Strength Cond. Res. 2020. [CrossRef] [PubMed]

7. Maloney, S.J.; Fletcher, I.M.; Richards, J. A comparison of methods to determine bilateral asymmetries in vertical leg stiffness. J. Sports Sci. 2016, 34, 829-835. [CrossRef]

8. Bishop, C.; Read, P.; Brazier, J.; Jarvis, P.; Chavda, S.; Bromley, T.; Turner, A. Effects of Interlimb Asymmetries on Acceleration and Change of Direction Speed. J. Strength Cond. Res. 2019. [CrossRef] [PubMed]

9. Suchomel, T.J.; Nimphius, S.; Bellon, C.R.; Stone, M.H. The Importance of Muscular Strength: Training Considerations. Sports Med. 2018, 48, 765-785. [CrossRef]

10. Haff, G.G.; Nimphius, S. Training principles for power. Strength Cond. J. 2012, 34, 2-12. [CrossRef]

11. Nimphius, S.; Geib, G.; Spiteri, T.; Calisle, D. 'Change of direction deficit' measurement on Division I American football players. J. Aust. Strength Cond. 2013, 21, 115-117.

12. Bishop, C.; Read, P.; McCubbine, J.; Turner, A. Vertical and Horizontal Asymmetries are Related to Slower Sprinting and Jump Performance in Elite Youth Female Soccer Players. J. Strength Cond. Res. 2018. [CrossRef] [PubMed]

13. Dos'Santos, T.; Thomas, C.; Jones, P.A.; Comfort, P. Asymmetries in single and triple hop are not detrimental to change of direction speed. J. Trainol. 2017, 6, 35-41. [CrossRef]

14. Lockie, R.G.; Callaghan, S.J.; Berry, S.P.; Cooke, E.R.A.; Jordan, C.A.; Luczo, T.M.; Jeffriess, M.D. Relationship between unilateral jumping ability and asymmetry on multidirectional speed in team-sport athletes. J. Strength Cond. Res. 2014, 28, 3557-3566. [CrossRef] [PubMed]

15. Maloney, S.J.; Richards, J.; Nixon, D.G.D.; Harvey, L.J.; Fletcher, I.M. Do stiffness and asymmetries predict change of direction performance? J. Sports Sci. 2017, 35, 547-556. [CrossRef]

16. Madruga-Parera, M.; Bishop, C.; Fort-Vanmeerhaeghe, A.; Beltran-Valls, M.; Skok, O.; Romero-Rodríguez, D. Interlimb Asymmetries in Youth Tennis Players: Relationships with Performance. J. Strength Cond. Res. 2019. [CrossRef]

17. Dos'Santos, T.; Thomas, C.; Jones, P.A.; Comfort, P. Assessing Asymmetries in Change of Direction Speed Performance: Application of Change of Direction Deficit. J. Strength Cond. Res. 2019, 33, $2953-2961$. [CrossRef]

18. Bishop, C.; Turner, A.; Maloney, S.; Lake, J.; Loturco, I.; Bromley, T.; Read, P. Drop Jump Asymmetry is Associated with Reduced Sprint and Change-of-Direction Speed Performance in Adult Female Soccer Players. Sports 2019, 7, 29. [CrossRef]

19. Dos'Santos, T.; Christopher, T.; Comfort, P.; Jones, P.A. Comparison of Change of Direction Speed Performance and Asymmetries between Team-Sport Athletes: Application of Change of Direction Deficit. Sports 2018, 6, 174. [CrossRef]

20. Turner, A.N.; Stewart, P.F. Strength and conditioning for soccer players. Strength Cond. J. 2014, 36, 1-13. [CrossRef]

21. Read, P.J.; Hughes, J.; Stewart, P.; Chavda, S.; Bishop, C.; Edwards, M.; Turner, A.N. A needs analysis and field-based testing battery for basketball. Strength Cond. J. 2014, 36, 13-20. [CrossRef]

22. Roberts, T.; Turner, A.; Mayers, R. A field based test battery for tennis. Prof. Strength Cond. 2011, $20,13-22$. 
23. Sarabon, N.; Rosker, J.; Fruhmann, H.; Burggraf, S.; Loefler, S.; Kern, H. Reliability of maximal voluntary contraction related parameters measured by a novel portable isometric knee dynamometer. Phys. Med. Rehabil. Kurortmed. 2013, 23, 22-27. [CrossRef]

24. Cormack, S.; Newton, R.; McGuigan, M.; Doyle, T. Reliability of measures obtained during single and repeated countermovement jumps. Int. J. Sports Physiol. Perform. 2008, 3, 131-144. [CrossRef] [PubMed]

25. Koo, T.K.; Li, M.Y. A Guideline of Selecting and Reporting Intraclass Correlation Coefficients for Reliability Research. J. Chiropr. Med. 2015. [CrossRef] [PubMed]

26. Kovacs, M. Movement for Tennis: The Importance of Lateral Training. Strength Cond. J. 2009, 31, 77-85. [CrossRef]

27. Johnson, C.D.; McHugh, M.P. Performance demands of professional male tennis players. Br. J. Sports Med. 2006, 40, 696-699. [CrossRef]

28. Madruga-Parera, M.; Romero-Rodríguez, D.; Bishop, C.; Beltran-Valls, M.R.; Latinjak, A.T.; Beato, M.; Fort-Vanmeerhaeghe, A. Effects of Maturation on Lower Limb Neuromuscular Asymmetries in Elite Youth Tennis Players. Sports 2019, 7, 106. [CrossRef]

29. Ekstrand, J.; Hägglund, M.; Waldén, M. Injury incidence and injury patterns in professional football: The UEFA injury study. Br. J. Sports Med. 2011, 45, 553-558. [CrossRef]

30. Croisier, J.L.; Ganteaume, S.; Binet, J.; Genty, M.; Ferret, J.M. Strength imbalances and prevention of hamstring injury in professional soccer players: A prospective study. Am. J. Sports Med. 2008, 36, 1469-1475. [CrossRef]

31. Ribeiro-Alvares, J.B.; Dornelles, M.; Fritsch, C.; de Lima-E-Silva, F.; Medeiros, T.; Severo-Silveira, L.; Marques, V.; Baroni, B. Prevalence of Hamstring Strain Injury Risk Factors in Professional and Under-20 Male Football (Soccer) Players. J. Sport Rehabil. 2019. [CrossRef] [PubMed]

32. Gathercole, R.; Spored, B.; Stelligwerff, T.; Sleivert, G. Comparison of the Capacity of Different Jump and Sprint Field Tests to Detect Neuromuscular Fatigue. J. Strength Cond. Res. 2015, 29, 2522-2531. [CrossRef] [PubMed]

33. Bodor, M. Quadriceps protects the anterior cruciate ligament. J. Orthop. Res. 2001, 19, 629-633. [CrossRef]

34. Joseph, A.M.; Collins, C.L.; Henke, N.M.; Yard, E.E.; Fields, S.K.; Comstock, R.D. A multisport epidemiologic comparison of anterior cruciate ligament injuries in high school athletics. J. Athl. Train. 2013, 48, 810-817. [CrossRef] [PubMed]

35. Moses, B.; Orchard, J.; Orchard, J. Systematic review: Annual incidence of ACL injury and surgery in various populations. Res. Sports Med. 2012, 20, 157-179. [CrossRef] 